\title{
Redox Cycling within Nanoparticle-Nucleated Protein Superstructures: Electron Transfer between Nanoparticulate Gold, Molecular Reductant, and Cytochrome $\mathrm{c}^{1}$
}

\author{
Amanda S. Harper-Leatherman, *, Jean Marie Wallace, ${ }^{\ddagger 2}$ Jeffrey W. Long, ${ }^{*}$ \\ Christopher P. Rhodes, ${ }^{\ddagger}$ Molly E. Graffam, ${ }^{\dagger}$ Bayan H. Abunar, ${ }^{\dagger}$ and Debra R. Rolison ${ }^{*}, *$ \\ $\dagger$ Fairfield University, Department of Chemistry and Biochemistry, 1073 North Benson Road, Fairfield, \\ CT 06824, USA \\ * Nova Research, Inc., 1900 Elkin Street, Alexandria, VA 22308, USA \\ * U. S. Naval Research Laboratory, Surface Chemistry Branch, Washington, DC 20375, USA \\ ¥ Department of Chemistry and Biochemistry, Texas State University, San Marcos, TX 78666, USA
}

\section{SUPPORTING INFORMATION}

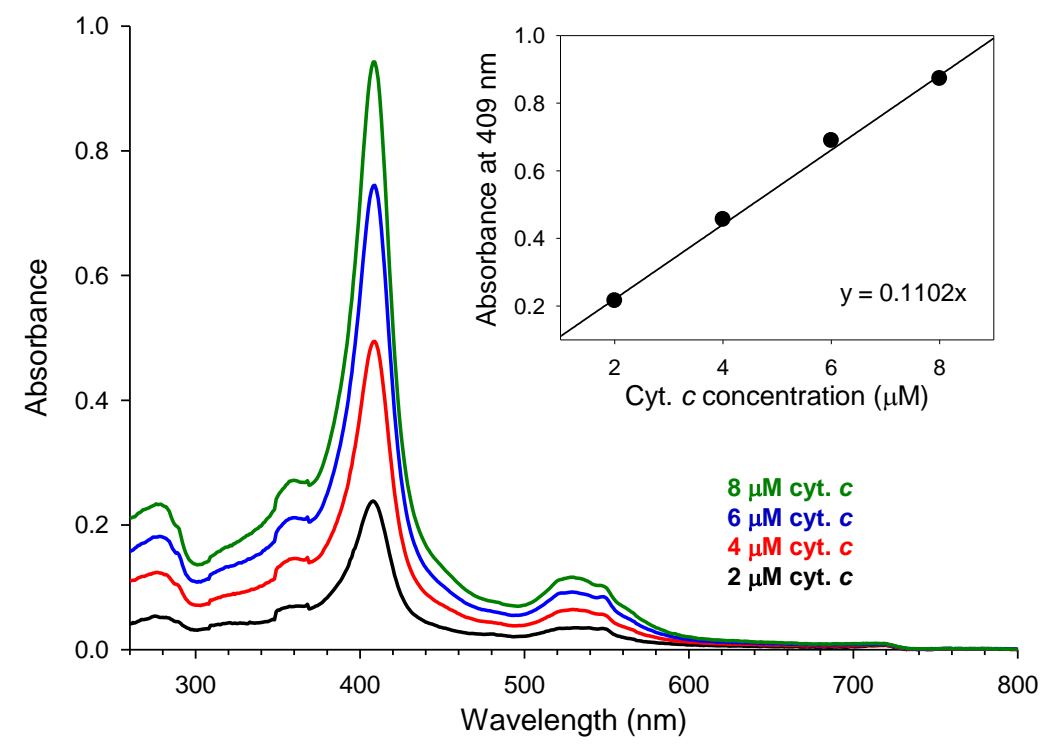

Figure S1. The UV-Vis spectra of $A u_{(5-n m)} \sim c y t . c$ aqueous suspensions as the concentration of cyt. $c$ is varied ( $8 \mu \mathrm{M}$ (green), $6 \mu \mathrm{M}$ (blue), $4 \mu \mathrm{M}$ (red), and $2 \mu \mathrm{M}$ (black)) and the number ratio of Au nanoparticles to molecules of cyt. $c$ is kept constant at 5700 cyt. $c$ molecules per Au nanoparticle. The suspension density of Au nanoparticles in each composite is $8.4 \times 10^{11} \mathrm{Au} \mathrm{mL} \mathrm{m}^{-1}, 6.5 \times 10^{11} \mathrm{Au} \mathrm{mL} \mathrm{L}^{-1}, 4.3 \times 10^{11} \mathrm{Au} \mathrm{mL}^{-1}$, and $2.2 \times 10^{11} \mathrm{Au} \mathrm{mL} \mathrm{m}^{-1}$, respectively. The inset shows the absorbance at $409 \mathrm{~nm}$ (from a baseline at $495 \mathrm{~nm}$ ) versus concentration of cyt. $c$; a best-fit line is shown in which the $y$-intercept is set to zero.

${ }^{1}$ In celebration of Emily A. Carter's $60^{\text {th }}$ birthday and with warm respect for her fearless computational prowess, including bringing the efficiency of density functional embedding theory to systems too large for high-level quantum calculations, including those in biochemistry.

2 Current address: Virginia Department of Forensic Science, Northern Lab, 10850 Pyramid Place, Manassas, VA 20110, USA

*Corresponding authors: aharper@fairfield.edu; rolison@nrl.navy.mil. 


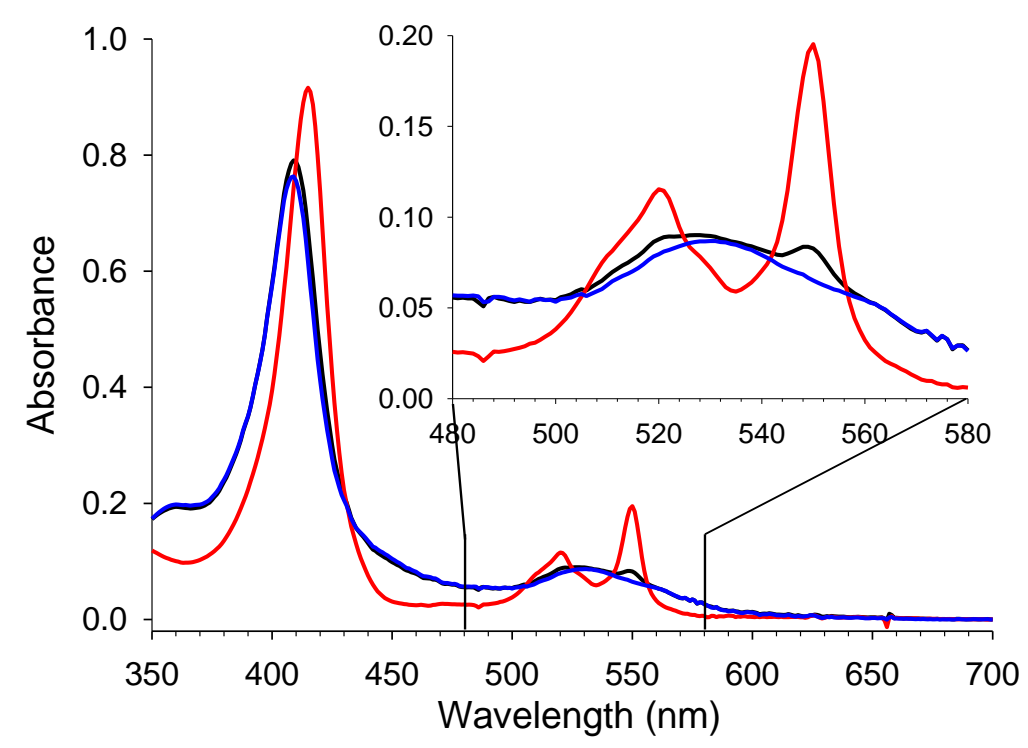

Figure S2. The UV-Vis spectra of Au cyt. $c$ superstructures in buffered medium with and without the addition of reductant (sodium hydrosulfite) and oxidant (potassium ferricyanide). (red) Chemically reduced $\mathrm{Au}_{(5-\mathrm{nm})} \sim \mathrm{cyt}$. $c$ ( $0.24 \mathrm{mM}$ sodium hydrosulfite $+8 \mu \mathrm{M}$ cyt. $c+1.1 \times 10^{12} \mathrm{Au}_{(5-\mathrm{nm})} \mathrm{mL}^{-1}$ [one gold nanoparticle per 4500 cyt. $c$ molecules]); this spectrum is multiplied by 0.75 for comparison with other spectra; (black) $\mathrm{Au}_{(5-\mathrm{nm})} \sim \mathrm{cyt}$. $c\left(6 \mu \mathrm{M}\right.$ cyt. $c+6.5 \times 10^{11} \mathrm{Au}_{(5-\mathrm{nm})} \mathrm{mL}^{-1}$ [one gold nanoparticle per 5700 cyt. $c$ molecules]); (blue) Chemically oxidized $\mathrm{Au}_{(5-\mathrm{nm})} \sim$ cyt. $c(4 \mu \mathrm{M}$ potassium ferricyanide $+6 \mu \mathrm{M}$ cyt. $c+6.5 \times 10^{11} \mathrm{Au}_{(5-\mathrm{nm})} \mathrm{mL}^{-1}$ [one gold nanoparticle per 5700 cyt. $c$ molecules]). The spectra are normalized at $700 \mathrm{~nm}$. The inset shows the peak changes more clearly in the 480-580-nm region of the spectra.

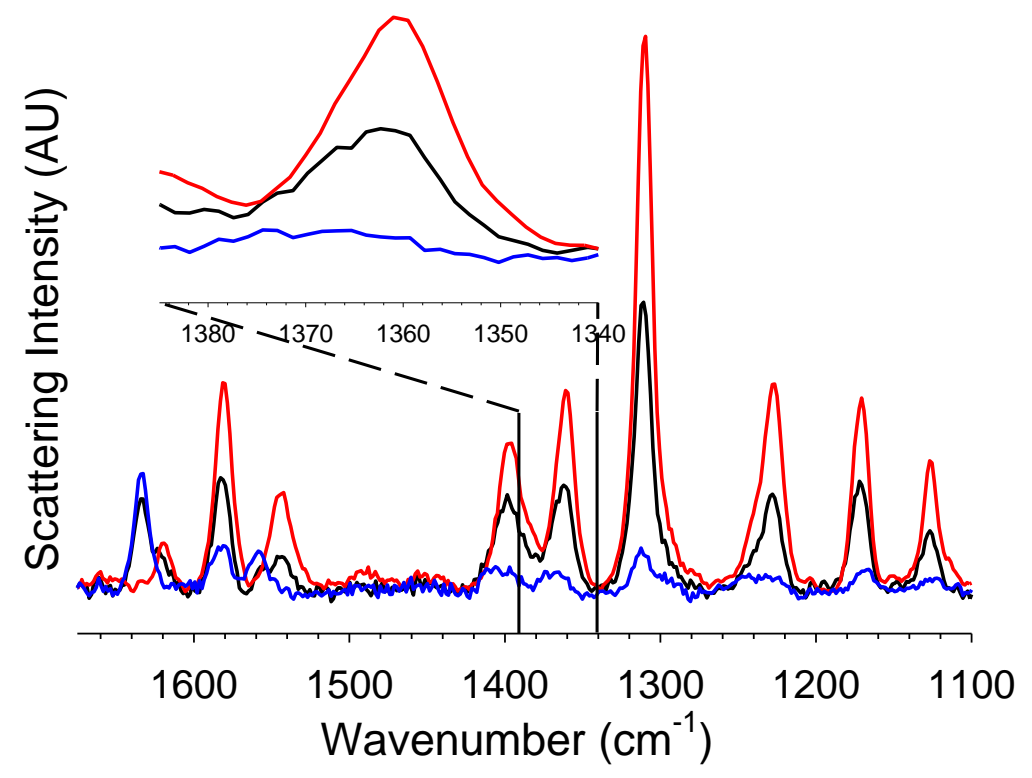

Figure S3. Resonance Raman spectra of Au cyt. $c$ superstructures in $50 \mathrm{mM}$ buffer with and without addition of reductant (sodium hydrosulfite) or oxidant (potassium ferricyanide). (red) Chemically reduced $\mathrm{Au}_{(5-\mathrm{nm})} \sim \mathrm{cyt}$. $c$ (0.24 mM sodium hydrosulfite $+8 \mu \mathrm{M}$ cyt. $c+1.1 \times 10^{12} \mathrm{Au} \mathrm{mL} \mathrm{m}^{-1}$ [4500 cyt. $c$ molecules per Au nanoparticle]); data obtained using 30-s acquisition times averaged over 30 accumulations. (black) $\mathrm{Au}_{(5-\mathrm{nm})} \sim \mathrm{cyt}$. $c\left(10 \mu \mathrm{M}\right.$ cyt. $c+1.1 \times 10^{12} \mathrm{Au} \mathrm{\textrm {mL } ^ { - 1 }}$ (5700 cyt. $\mathrm{c}$ molecules per Au nanoparticle]; data obtained using 50-s acquisition times averaged over 50 accumulations). (blue) Chemically oxidized $\mathrm{Au}_{(5-\mathrm{nm})} \sim$ cyt. $c\left(7 \mu \mathrm{M}\right.$ potassium ferricyanide $+10 \mu \mathrm{M}$ cyt. $c+1.1 \times 10^{12} \mathrm{Au} \mathrm{mL}^{-1}$ (5700 cyt. $c$ molecules per Au nanoparticle); data obtained using 50-s acquisition times averaged over 50 accumulations). The spectra are normalized at $1675 \mathrm{~cm}^{-1}$. 


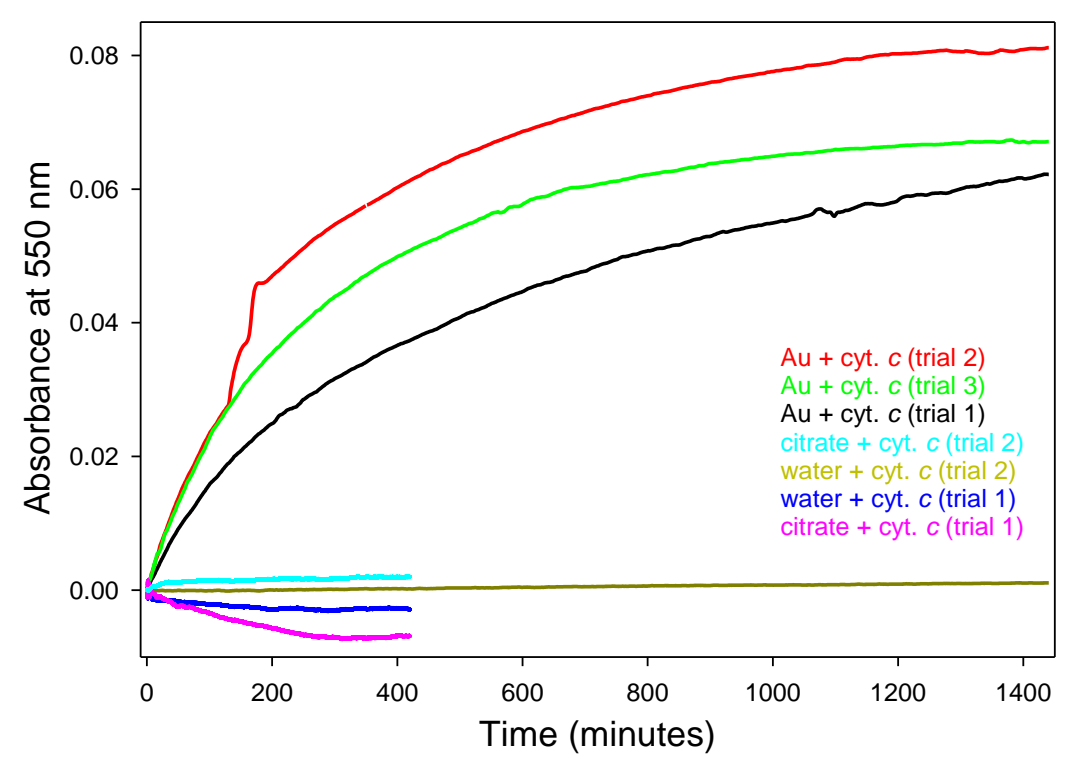

Figure S4. The visible absorbance at $550 \mathrm{~nm}$ of cyt. $c$ (starting from a stock solution in $25 \mathrm{mM}$ buffer) in the presence of different species as monitored over time: (black, trial 1; red, trial 2; green, trial 3) $\mathrm{Au}_{(5-\mathrm{nm})} \sim \mathrm{cyt}$. $c$ (6 $\mu \mathrm{M}$ cyt. $c+6.3 \times 10^{11} \mathrm{Au} \mathrm{mL} \mathrm{L}^{-1}$ [5700 cyt. $c$ molecules per nanoparticle]); (cyan) $6 \mu \mathrm{M}$ cyt. $c+8.5 \mathrm{mM}$ citrate; (blue, trial 1; dark yellow, trial 2) $6 \mu \mathrm{M}$ cyt. $c$ in water; (pink) $6 \mu \mathrm{M}$ cyt. $c+31 \mu \mathrm{M}$ citrate. 


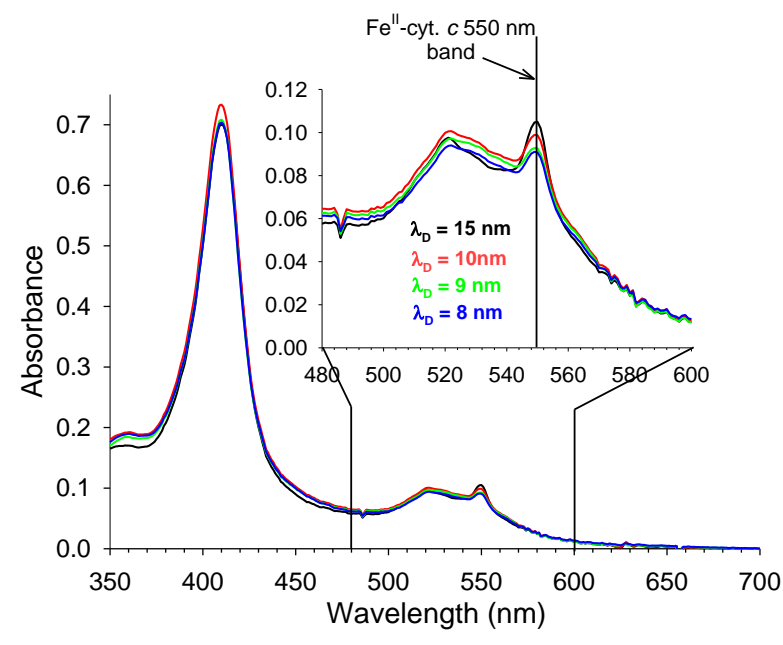

Figure S5. The UV-Visible spectra of $A u_{(5-n m)} \sim$ cyt. $c$ superstructures at a constant ratio of 3300 cyt. $c$ per Au nanoparticle as the ionic strength of the microheterogeneous medium is varied. To make the Au cyt. $c$ superstructures, $1.1 \times 10^{12} \mathrm{Au} \mathrm{mL}$ is combined with cyt. $c$ in (black) $25 \mathrm{mM}$ phosphate buffer, (red) $50 \mathrm{mM}$ phosphate buffer, (green) $75 \mathrm{mM}$ phosphate buffer, and (blue) $100 \mathrm{mM}$ phosphate buffer (final cyt. $c$ concentration is $6 \mu \mathrm{M}$; the colloidal suspension density remains constant at $1.1 \times 10^{12} \mathrm{Au} \mathrm{mL}-1$ for all). The spectra are normalized at $700 \mathrm{~nm}$. Inset: Fe"ll-cyt. $c$ band at $550 \mathrm{~nm}$ listing the Debye screening length $\left(\lambda_{D}\right)$.

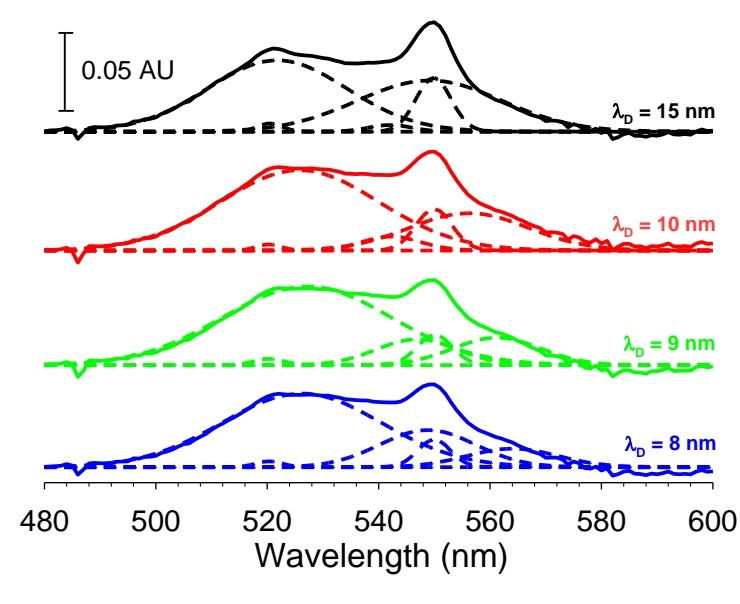

Figure S6. The Gaussian fits to the UV-Visible spectra shown in Figure $\mathrm{S}-5$ of $\mathrm{Au}_{(5-\mathrm{nm})} \sim \mathrm{cyt}$. $c$ superstructures as the ionic strength of the aqueous composite is varied. To make the Au cyt. $c$ superstructures, $1.1 \times 10^{12} \mathrm{Au} \mathrm{mL} \mathrm{L}^{-1}$ is combined with cyt. $c$ in (black) $25 \mathrm{mM}$ phosphate buffer, (red) $50 \mathrm{mM}$ phosphate buffer, (green) $75 \mathrm{mM}$ phosphate buffer, and (blue) $100 \mathrm{mM}$ phosphate buffer. After combining cyt. $c$ and gold, the final cyt. $c$ concentration is $6 \mu \mathrm{M}$ in each case, and the colloid remains at $1.1 \times 10^{12} \mathrm{Au} \mathrm{mL} L^{-1}$, resulting in 3300 cyt. $c$ per nanoparticle. The initial cyt. $c$ solution used to make the Au cyt. $c$ superstructures varies in ionic strength, and therefore the final Au cyt. $c$ aqueous composites vary in the Debye screening length as shown in the figure. The four spectra are offset on the $y$-axis for clarity. The dashed lines under each curve represent the Gaussian fit in the wavelength region displayed. 


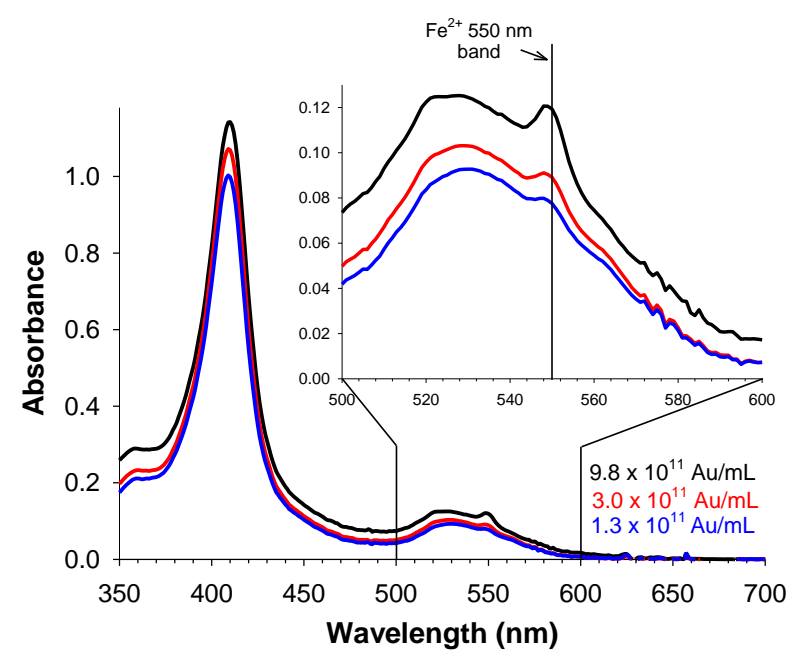

Figure S7. The UV-Visible spectra of $A u_{(5-n m)} \sim$ cyt. $c$ superstructures as the number ratio of to cyt. $c$ (in $50 \mathrm{mM}$ phosphate buffer) to Au nanoparticle is varied. (black) 5700 cyt. $c$ molecules per gold nanoparticle $\left(9.3 \mu \mathrm{M}\right.$ cyt. $c$ and $\left.9.8 \times 10^{11} \mathrm{Au} \mathrm{mL}^{-1}\right)$; (red) 19000 cyt. $c$ molecules per gold nanoparticle $(9.3 \mu \mathrm{M}$ cyt. $c$ and $3.0 \times 10^{11} \mathrm{Au} \mathrm{mL} \mathrm{m}^{-1}$ ); (blue) 44000 cyt. $c$ molecules per gold nanoparticle $\left(9.3 \mu \mathrm{M}\right.$ cyt. $c$ and $1.3 \times 10^{11} \mathrm{Au} \mathrm{\textrm {mL } ^ { - 1 }}$ ). The spectra are normalized at $700 \mathrm{~nm}$. The inset shows the Fe" -cyt. $c$ band at $550 \mathrm{~nm}$ more clearly.

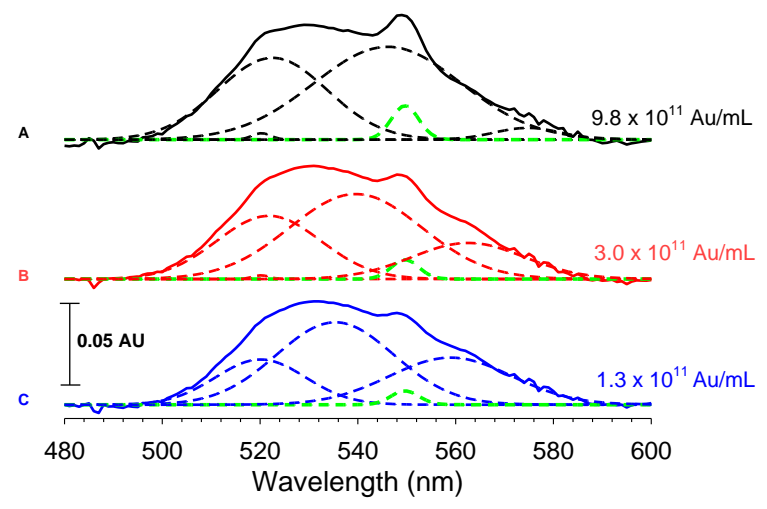

Figure S9. Gaussian fits to the UV-Visible spectra shown in Figure $\mathrm{S7}$ of $\mathrm{Au}_{(5-\mathrm{nm})} \sim \mathrm{cyt}$. $c$ superstructures as the number ratio of cyt. $c$ to Au nanoparticle is varied. (black) 5700 cyt. $c$ molecules per gold nanoparticle $(9.3 \mu \mathrm{M}$ cyt. $c$ and $9.8 \times 10^{11} \mathrm{Au} \mathrm{mL} \mathrm{m}^{-1}$ ); (red) 19000 cyt. $c$ molecules per gold nanoparticle $(9.3 \mu \mathrm{M}$ cyt. $c$ and $3.0 \times 10^{11} \mathrm{Au} \mathrm{mL} \mathrm{m}^{-1}$ ); (blue) 44000 cyt. $\mathrm{c}$ molecules per gold nanoparticle $\left(9.3 \mu \mathrm{M}\right.$ cyt. $c$ and $\left.1.3 \times 10^{11} \mathrm{Au} \mathrm{mL}^{-1}\right)$. The three spectra are offset on the $y$-axis for clarity. The dashed lines under each curve represent the Gaussian fits in the wavelength region displayed.

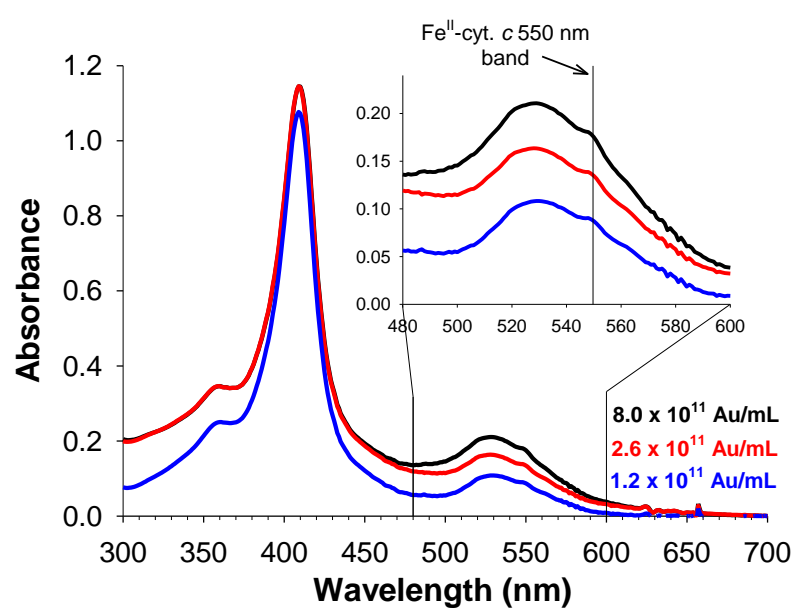

Figure S8. The UV-Visible spectra of $A u_{(10-n m)} \sim c y t . c$ superstructures as the number ratio of cyt. $c$ (in $50 \mathrm{mM}$ phosphate buffer) to Au nanoparticle is varied. (black) 7000 cyt. $c$ molecules per gold nanoparticle $(9.3 \mu \mathrm{M}$ cyt. $c$ and $8.0 \times 10^{11} \mathrm{Au} \mathrm{mL}^{-1}$ ). (red) 22000 cyt. $\mathrm{c}$ molecules per gold nanoparticle $(9.3 \mu \mathrm{M}$ cyt. $c$ and $2.6 \times 10^{11} \mathrm{Au} \mathrm{mL} \mathrm{L}^{-1}$ ). (blue) 49000 cyt. $c$ molecules per gold nanoparticle (9.3 $\mu \mathrm{M}$ cyt. $c$ and $1.2 \times 10^{11} \mathrm{Au} \mathrm{mL^{-1 }}$ ). The spectra are normalized at $700 \mathrm{~nm}$. The inset shows the Fe"-cyt. $c$ band at $550 \mathrm{~nm}$ more clearly.

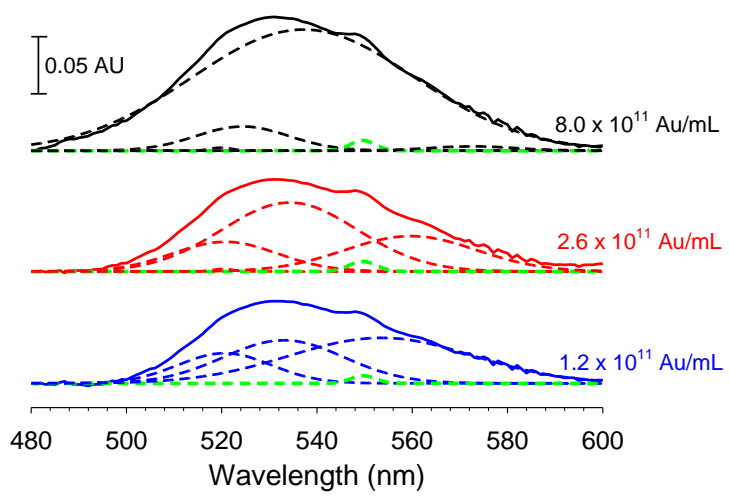

Figure S10. Gaussian fits to the UV-Visible spectra shown in Figure $\mathrm{S} 8$ of $A u_{(10-n m)} \sim$ cyt. $c$ in buffered media as the ratio of Au nanoparticle to cyt. $c$ is varied. (black) 7000 cyt. $c$ molecules per nanoparticle $(9.3 \mu \mathrm{M}$ cyt. $c$ and $8.0 \times 10^{11} \mathrm{Au} \mathrm{mL} \mathrm{L}^{-1}$ ). (red) 22000 cyt. $c$ molecules per nanoparticle (9.3 $\mu \mathrm{M}$ cyt. $c$ and $2.6 \times 10^{11} \mathrm{Au} \mathrm{mL} \mathrm{L}^{-1}$ ). (blue) 49000 cyt. $c$ molecules per Au nanoparticle $\left(9.3 \mu \mathrm{M}\right.$ cyt. $c$ and $\left.1.2 \times 10^{11} \mathrm{Au} \mathrm{mL}^{-1}\right)$. The three spectra are offset on the $y$-axis for clarity. The dashed lines under each curve represent the Gaussian fits in the wavelength region displayed. 
Table S-1. Effects of gold nanoparticle to cyt. $c$ ratio and buffer concentration on Fe"l-cyt. $c$ formation in Au cyt. $c$ suspension.

\begin{tabular}{|c|c|c|c|c|c|c|c|c|c|c|c|c|c|}
\hline $\begin{array}{c}\mathrm{Au} \\
\text { colloid } \\
\text { particle } \\
\text { diameter } \\
(\mathrm{nm})^{a}\end{array}$ & $\begin{array}{l}\text { Au colloid } \\
\text { particles per } \\
\text { volume } \\
\text { in Au cyt. } c \\
\text { reaction } \\
\text { volume } \\
\left(\mathrm{mL}^{-1}\right)\end{array}$ & $\begin{array}{c}\text { Number of } \\
\text { Au particles } \\
\text { in Au cyt. c } \\
\text { reaction } \\
\text { volume }^{c}\end{array}$ & $\begin{array}{l}\text { [cyt. c] } \\
\text { in Au cyt. c } \\
\text { reaction } \\
\text { volume }^{d} \\
(\mu \mathrm{M})\end{array}$ & $\begin{array}{l}\text { Number of } \\
\text { cyt. } c \text { in } \\
\text { Au cyt. } c \\
\text { reaction } \\
\text { volume }^{c}\end{array}$ & $\begin{array}{l}\text { Number of } \\
\text { cyt. } c \text { per Au } \\
\text { particle in } \\
\text { Au cyt. } c \\
\text { reaction } \\
\text { volume }\end{array}$ & $\begin{array}{c}\text { Number of } \\
\text { cyt. } c \text { shells } \\
\text { per Au } \\
\text { particle in } \\
\text { Au cyt. } c \\
\text { reaction } \\
\text { volume }^{e}\end{array}$ & $\begin{array}{l}\text { [Fell-cyt. } c \text { ] } \\
\text { formed in } \\
\text { Au } \sim \text { cyt. } c \\
\text { reaction } \\
\text { volume }^{f} \\
\quad(\mu \mathrm{M})\end{array}$ & $\begin{array}{l}\text { Number of } \\
\text { Fe"-cyt. } c \\
\text { formed in } \\
\text { Au cyt. } c \\
\text { reaction } \\
\text { volume }^{c}\end{array}$ & $\begin{array}{c}\text { Number of } \\
\text { electrons } \\
\text { extracted } \\
\text { per gold } \\
\text { nanoparticle } \\
g\end{array}$ & $\begin{array}{c}\text { Number of } \\
\text { gold atoms } \\
\text { per gold } \\
\text { particle }^{h}\end{array}$ & $\begin{array}{l}\text { Percentage } \\
\text { of gold } \\
\text { atoms } \\
\text { oxidized }\end{array}$ & $\begin{array}{l}\text { Concentration of } \\
\text { buffer used to } \\
\text { make initial cyt. c } \\
\text { solution } \\
\text { (M) }\end{array}$ & $\begin{array}{c}\text { Debye } \\
\text { screening } \\
\text { length }\left(\lambda_{D}\right) \text { in } \\
\text { Au } \sim \text { cyt. } c \\
\text { reaction }^{-1} \\
\text { volume }^{i}\left(\mathrm{~nm}^{-1}\right)\end{array}$ \\
\hline 10 & $8.0 \times 10^{11}$ & $1.4 \times 10^{12}$ & 9.3 & $1.0 \times 10^{16}$ & 7100 & 10 & 0.33 & $3.6 \times 10^{14}$ & 260 & 30900 & 0.84 & 0.05 & 8 \\
\hline 10 & $2.6 \times 10^{11}$ & $4.7 \times 10^{11}$ & 9.3 & $1.0 \times 10^{16}$ & 21000 & 15 & 0.32 & $3.5 \times 10^{14}$ & 740 & 30900 & 2.4 & 0.05 & 8 \\
\hline 10 & $1.2 \times 10^{11}$ & $2.2 \times 10^{11}$ & 9.3 & $1.0 \times 10^{16}$ & 45000 & 20 & 0.24 & $2.6 \times 10^{14}$ & 1200 & 30900 & 3.9 & 0.05 & 9 \\
\hline 5 & $9.8 \times 10^{11}$ & $1.8 \times 10^{12}$ & 9.3 & $1.0 \times 10^{16}$ & 5600 & 10 & 0.76 & $8.2 \times 10^{14}$ & 460 & 3900 & 12 & 0.05 & 9 \\
\hline 5 & $3.0 \times 10^{11}$ & $5.4 \times 10^{11}$ & 9.3 & $1.0 \times 10^{16}$ & 19000 & 15 & 0.44 & $4.8 \times 10^{14}$ & 890 & 3900 & 23 & 0.05 & 9 \\
\hline 5 & $1.3 \times 10^{11}$ & $2.3 \times 10^{11}$ & 9.3 & $1.0 \times 10^{16}$ & 43000 & 20 & 0.31 & $3.4 \times 10^{14}$ & 1500 & 3900 & 38 & 0.05 & 9 \\
\hline 5 & $1.1 \times 10^{12}$ & $2.2 \times 10^{12}$ & 6 & $7.2 \times 10^{15}$ & 3300 & 8 & 1.3 & $1.6 \times 10^{15}$ & 730 & 3900 & 19 & 0.025 & 15 \\
\hline 5 & $1.1 \times 10^{12}$ & $2.2 \times 10^{12}$ & 6 & $7.2 \times 10^{15}$ & 3300 & 8 & 0.98 & $1.2 \times 10^{15}$ & 550 & 3900 & 14 & 0.05 & 10 \\
\hline 5 & $1.1 \times 10^{12}$ & $2.2 \times 10^{12}$ & 6 & $7.2 \times 10^{15}$ & 3300 & 8 & 0.69 & $8.3 \times 10^{14}$ & 380 & 3900 & 9.7 & 0.075 & 9 \\
\hline 5 & $1.1 \times 10^{12}$ & $2.2 \times 10^{12}$ & 6 & $7.2 \times 10^{15}$ & 3300 & 8 & 0.65 & $7.8 \times 10^{14}$ & 350 & 3900 & 9.0 & 0.1 & 8 \\
\hline
\end{tabular}

a Gold colloids were purchased in varying particle diameters (BBI International) and stored in the dark at $4{ }^{\circ} \mathrm{C}$.

$b$ Derived from aqueous dilutions of the colloidal gold that was $5.7 \times 10^{12} 10-\mathrm{nm}$ particles per $\mathrm{mL}$ and $5.0 \times 10^{13} 5$ - $\mathrm{nm}$ particles per $\mathrm{mL}$ as purchased.

c $1800 \mu \mathrm{L}$ total solution in first six rows, $2000 \mu \mathrm{L}$ total solution in the last four rows.

$d$ This concentration is calculated on the basis of making the Au cyt. $c$ suspension by diluting the colloidal gold sol with a stock cyt. $c$ buffered solution. The stock solution was made by dissolving $0.023 \mathrm{~g}$ of cyt. c (horse heart, Type VI; Sigma Aldrich \#C 7752) in $2 \mathrm{~mL}$ of buffer. This stock solution primarily consisted of Fe'II-cyt. $c$ based on visible spectroscopy. The concentration of the stock solution was calculated from its visible spectrum using an extinction coefficient of $106100 \mathrm{M}^{-1} \mathrm{~cm}^{-1}$ for the Soret

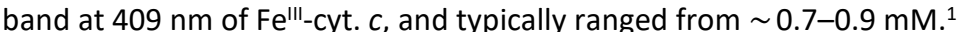

$e$ The first protein shell is a monolayer of cyt. $c$ that specifically adsorbs at the nanoparticle. The number of cyt. $c$ in this first shell is calculated from the number of cyt. $c$ $\left(9.08 \mathrm{~nm}^{2}\right.$ cross-sectional area) that can fit on the surface area of the spherical particle. The number of cyt. $c$ in the second shell (or layer) is calculated based on the number of cyt. $c$ that can fit on the surface area of the newly formed sphere (monolayer plus nanoparticle) of larger diameter that equals the diameter of the nanoparticle plus two diameters of cyt. $c$. The number of cyt. $c$ in subsequent shells is calculated in a similar way based on the growing diameter of the sphere.

${ }^{f}$ Calculated from Gaussian fitted visible absorbance at $550 \mathrm{~nm}$ of Fe"l-cyt. $c$ using an extinction coefficient of $27500 \mathrm{M}^{-1} \mathrm{~cm}^{-1}{ }^{2} \mathrm{Absorbances}$ from the top to the bottom of the table were $9.0 \times 10^{-3}, 8.9 \times 10^{-3}, 6.7 \times 10^{-3}, 0.021,0.012,8.4 \times 10^{-3}, 0.033,0.027,0.019$, and 0.018 .

$g$ This number is equivalent to the number of Fe"l-cyt. $c$ formed per Au nanoparticle in the Au cyt. $c$ reaction volume.

${ }^{h}$ Calculated using the volume of each gold particle (assuming each particle is a sphere where, volume $\left.=4 / 3 \pi \mathrm{r}^{3}\right)$, the density of gold $\left(19.3 \mathrm{~g} \mathrm{~mL}^{-1}\right.$ ), the molecular weight of gold (196.97 $\mathrm{g} \mathrm{mol}^{-1}$ ), and Avogadro's number to determine the number of atoms of gold in each particle.

1 Calculated from $\lambda_{D}=1 /\left(4 \pi I_{B} \sum z_{i}^{2} \rho_{i}\right)^{1 / 2}$ where $I_{B}$ is the Bjerrum length $\left(0.7 \mathrm{~nm}\right.$ in aqueous solution at standard pressure and temperature), $z_{i}$ is ion charge, and $\rho_{i}$ is ionic number density taking into account the buffer ions, $\mathrm{NaH}_{2} \mathrm{PO}_{4}, \mathrm{Na}_{2} \mathrm{HPO}_{4}$, and the ions from the gold sol, $\mathrm{HCl}$. 


\section{REFERENCES}

(1) Margoliash, E.; Frohwirt, N. Spectrum of Horse-Heart Cytochrome c. Biochem. J. 1959, 71, 570-572.

(2) Butt, W. D.; Keilin, D. Absorption Spectra and Some Other Properties of Cytochrome c and of Its Compounds with Ligands. Proc. Royal Soc. London, Ser. B, Biol. Sci. 1962, 156, 429-458. 